\title{
Modern Empowerment in the Workplace
}

\author{
Kanika Maheshwari* \\ Department of Commerce, CCS University, Meerut, U.P., India \\ Email Id:kanika.mh31@gmail.com
}

\begin{abstract}
Empowering your employees is a great way to improve employee engagement and retain your top talent. Employers and employees both have unrealistic perceptions about what empowerment is and how it's supposed to work in real-time. Empowerment is the process of enabling or authorizing an individual to think, behave, take action, and control work and decision-making about their job in autonomous, independent, selfdirected ways. It is the state of feeling self-empowered to take control of your destiny.
\end{abstract}

Key Words: bestowing, embrace, foster, empowerment, work in realtime, unrealistic perceptions

PAPER/ARTICLE INFO RECEIVED ON: 07/04/2020 ACCEPTED ON: 28/05/2020

Reference to this paper should be made as follows:

Kanika Maheshwari (2020), "Modern Empowerment in the Workplace", Int. J. of Trade and Commerce-IIARTC, Vol. 9, No. 1, pp. 184-190 


\section{INTRODUCTION}

Empowerment is predicated on the thought that providing staff with the resources, authority, chance, and motivation to try and do their work, likewise as holding them in control of their actions, can create staff happier and more adept. In different words, permitting staff to require leadership of their roles ends up in high impact and long positive effects for the corporate and its people. Empowerment is often understood as knowledge-sharing, improvement of intellectual talents, and autonomy in decision-making-however, some researchers counsel to understand it as a stimulating issue instead of mere delegation. Employees' authorization is seen as a psychological feature observe to boost potency by facilitating opportunities for collaborating and interesting in decision-making. It's associated primarily with the event of trust, motivation, participation in decision-making, and bridging gaps between staff and high management. Empowerment is feeling control | on top of things | up to speed | up to the mark |au fait\} of your work atmosphere which you've got permission to form selections within the square measures you control and are chargeable for in your job. When wondering authorization in human relations terms, try and avoid thinking of it as one thing that one individual will for an additional. This attitude is one of the issues organizations have with the authorization construct. Individuals believe that somebody, typically the manager, must bestow authorization on the folks that report back to them.

Consequently, the reportage employees members await the giving of approval, and therefore the manager asks why individuals will not act in authorized ways that. This bestowing and waiting has light-emitting diode to general unhappiness, largely unmerited, with the construct of authorization in several organizations. Do not let that happen in your organization. Your best success can result from authorized staff taking action - not expecting permission.

Importance of authorization within the Workplace:

- Go the additional mile to succeed in the company's goals

- Follow best practices for up collaboration within the geographical point

- Improve their performance

- Drive effective communication within the geographic point

- Embrace changes like digital transformation or mergers and acquisitions

- Spread a positive perspective throughout the geographical point

- Provide higher client service

- Drive innovation

- Advocate for the whole Levels of authorization within the Workplace:

Structure Level - a company that cultivates worker authorization, will better:

- Embrace amendment like digital transformation

- Recognize employees' contribution to the business

- Reward accountable possession within the geographical point

- Support collaboration, together with cross-departmental cooperation within the geographic point

- Foster a culture of worker engagement

- Retain high talent

Social control Level - authorized team leaders can:

- Better support the team and facilitate every team member to reach their targets

- Provide the data the groups would like once they would like it

- Inspire and inspire staff 
Kanika Maheshwari

- Help higher connect staff, together with those operating remotely

- Facilitate work processes

- Spread shared aims within the geographical point

- Better communicate the business goals and long vision

- Make the groups a lot of palmy 3. Individual Level - once staff feel authorized and trustworthy, they:

- Are a lot of willing to travel the additional mile for the team and therefore the business

- Take possession over their work

- Generate concepts

- Know the way to take prudent risks to require the company to the following Level

- Find that means and purpose at work

- Feel pleased with the corporate they are engaging at

- Feel a lot of actuated and engaged Empowerment on the structure and social control levels ought to exist by default. However, achieving individual authorization needs way more work and energy, and it involves many functions within the organization.

\section{The Role of Company Culture}

Worker authorization Your company culture plays an essential role in worker authorization. If you would like to support your employees' performance, facilitate them to realize that means at work, and perceive. However, their jobs impact the business; you would like to foster the "right" company culture for that. And by the "right" company culture, I mean a corporate culture that supports innovation within the geographical point, employees' well-being, and helps them take initiatives at work. But confine mind that building a corporate culture that supports worker authorization does not come back nightlong. First, we'll have to incorporate worker authorization in your business goals. Think about it: if we would like to empower our staff, we'll have 1st to form it one amongst your high priorities! Making authorization within the geographical point, one amongst our business goals is one amongst the most effective ways that to one. Decide to it a pair of. Certify that everybody understands that work authorization could be a high priority for the corporate. Then, we'll have to make an enclosed communication that enhances worker authorization. And to succeed in this goal, we'll have to form positive that your I.C. strategy involves H.R. and I.C. functions; however, line managers likewise. Indeed, the approach we speak to our staff and, therefore, the initiatives we are taking to motive and encourage them incorporates a direct impact on however staff's feelings regarding their jobs, their managers, and consequently the company overall. When it involves authorization within the geographical point, managers and team leaders play an essential role. That is not stunning that communication skills square measure sound unit of the foremost in-demand soft skills.

I. How To Empower Employees: to provide authority associated possession by handing out responsibility- Let a worker war a replacement project - and run with it. Once you delegate different (even small) tasks to associate workers, it empowers her to urge the work done and done well.

II. Build tips and best practices clear- once staff perceives the directions, they must work inside and that boundary they will push, they can do their job a lot of effectively and feel a lot of support.

III. Encourage communication to extend levels of trust and show that every one ideas area unit welcome and valued. 
IV. Provide individual or team coaching job to spot roadblocks, realize solutions, so take action.

V. permit opportunities for growth- Foster internal development and growth across departments with cross-department job shadows and transitions.

VI. offers structure support for workers to make and drive their development plans with their managers.

Ways to spice up directly within the Workplace:

1. Delegate work and responsibility: Delegation and direction within the geographic point go hand in hand. Once associate degree worker clearly understands what tasks they're liable for, they take possession of their work. This enables you to manage their progress less as a result of you've got already shown that you simply trust in their ability to induce the duty done. Whereas this could seem to be a little thought to you, it suggests that everything to your staff. Our surveys have shown that solely five-hundredths of staff trust their leaders. Once you believe your team, it encourages them to trust you.

2. Set clear boundaries and expectations: several employers hesitate to empower their geographic point as a result of it will seem to be giving staff play to try and do no matter what they require. To stop this, ensure to outline project boundaries and also the results you expect your staff to supply. This can facilitate your commonplace of quality.

3. Guarantee staff have correct resources: simply because you've got shown them the pool, it doesn't suggest they will swim simply nonetheless. Develop a well of resources and toolsand show them the way to use those resources - for your staff to access whenever they have it. To boot, you ought to forever encourage open communication and let your team understand that you are offered for group activity sessions.

4. Be flexible: currently that you've got delegated work and established ground rules, you'll be able to begin cultivating a lot of relaxed, casual geographic point. If an associate degree worker must work from home, or needs a lot of versatile schedules, work with them to accommodate those desires. This helps your staff feel that you simply worth their lives outside work entirely; you worth pettifogging the principles.

5. Specialize in the results, not the process: Nothing kills worker direction quite like micromanaging. You've got already set the guidelines - let your staff select the way to work inside them. This can empower staff to figure in a|during a|in associate degree exceedingly|in a very\} means that is ideal for the individual instead of following an impersonal method. After all, the finished product is a lot of necessary than the steps it took to create it.

6. Embrace staff in special projects: Recent survey results show that staff World Health Organization feels a way of happiness at work area unit five. 3 times a lot of doubtless to feel sceptered to allow their best performance. Together with staff in distinctive could be a fantastic thanks to facilitating them feel appreciated, which their insight is valuable. It conjointly rejuvenates the work ethic by introducing the team to new folks and concepts. Our polls have conjointly found that staff World Health Organization participate in particular comes area unit seventieth a lot of doubtless to believe their job is getting ready them for his or her future career-and, as a result, sixty-seven of staff World Health Organization participate in particular comes to need to remain with their organization.

7. Be receptive input and innovation: Once your staff area unit was given the liberty to explore their work, you may be stunned by the insight they gain. Encourage staff to be open with their ideas concerning problem-solving ways, processes, and solutions. You will find that 
their distinctive "ground-level" perspective directly informs their innovation and creative thinking.

8. Offer cross-training and learning opportunities: folks wish to want they are moving forward in their careers. Encourage your staff to change and take a lively interest in different departments. This allows staff to develop and hone their skills - and offers you diverse team members the World Health Organization area unit wanting to utilize their abilities in their work.

9. Offer feedback and acknowledge excellence: Our survey results have shown that seventy-nine of individuals World Health Organization quit their jobs offer "lack of appreciation" because the reason for his or her resignations - this is extraordinarily distressing as a result of, in one study, sixty-fifths of North Americans rumored that they weren't recognized even once in a whole year. Do not be back concerning recognition. If you show your sincere appreciation for above-and-beyond work, your staff can repay you by repetition or perhaps up to their performance. They're going to conjointly feel sceptered as a result of they were rewarded for achievements they accomplished while not substantial oversight.

10. Be consistent: direction isn't an award associate degree leader will offer or exclude on a whim. Whereas tiny changes area unit okay, your staff will not feel genuinely sceptered if they understand their autonomy may well be revoked at any moment. And whereas exceptional performance ought to be rewarded, each worker ought to fancy the same necessary privileges to take care of a way of unity and inclusivity in your geographic point.

\section{RESPONSIBILITIES OF H.R. Professionals}

3.1. Participate in designing and Development In the trendy marketplace; human resource executives function strategic partners. They participate in the identification, development, and execution of company objectives. During this capability, H.R. executives align the work of their business unit to realize company goals. Participation in company designing permits human resource leaders to achieve a profound understanding of the structure activities required to help within the property growth of the enterprise.

3.2. Offer staff with Career Assistance. Periodically, human resource leaders conduct employee evaluations. Today, H.R. professionals take an active role in serving to staff advance their careers. Rather than merely grading staff on a list of performance points, fashionable human resource specialists facilitate team establish areas for improvement and develop specific action steps. By serving to staff with career development, modern H.R. professionals gain a lot of in-depth insight into offered human capital and also the availableness of internal candidates for potential role succession. This enables organizations to be told a marked advantage in filling future roles and meeting future market demands.

3.3. Realize and Recruit staff. That Advance Company Objectives-Today's human resource executives do entirely post ads and interview job candidates to fill open positions. Modern H.R. executives formulate leader brands designed to draw in the correct job candidates. During this responsibility, human resource leaders work to push their several corporations as extremely favorable workplaces. H.R. executives usually earn this sort of honor for organizations by making a positive culture and providing satisfactory compensation and edges as ways in which to draw in ideal work candidates. 
3.4. perform Leaders of Change. Modern human resource leaders frequently lead modification initiatives for his or her organizations. As a result, current H.R. executives yield strong project management skills in their company toolboxes. The professional's square measure consummate at serving to structure stakeholders create the affiliation between modification initiatives and strategic desires, minimizing modification resistance and worker unrest. Shaping structure culture, managing employee satisfaction, and deliberation the success of modification initiatives square measure all an area of the human resource professional's scope of responsibility within the current work.

3.5. Advocate for Employees. While fulfilling their roles as worker advocates, H.R. executives play AN integral half within the success of organizations. During this regard, human resource professionals contribute to putting together a piece setting wherever workers feel happy and driven. To push this outcome, H.R. leaders deploy effective practices like worker authorization, goal setting, and open communication, leading to a positive culture that results in the personnel delivering higher client experiences.

3.6. offer Support for violence Victims. The Centers for sickness management (CDC) forecasts that violence will affect one in four ladies and one in seven men within you. S.. the difficulty has full-grown, therefore prevailing that employers will now not afford to think about violence as a matter best left to the native authorities. As a result, today's H.R. professionals encourage those who've skilled force to hunt facilitate within the work. To promote this, human resource professionals promote AN structure culture wherever employees members don't feel intimidated or dishonored to approach to H.R. workers with violence issues.

3.7. guarantee No Cyberbullying At Work. Traditionally, work intimidation came about only within the Workplace. Today, however, the property of the web extends the influence of bullies to victims' workstations and houses, AN activity known as cyberbullying. Workers and supervisors apprehend that this may happen within the work, nevertheless addressing Workplace cyberbullying might prove difficult. Despite this, up to date, human resource executives attempt to eliminate this type of harmful activity within the work.

\subsection{Examples of Employee Empowerment:}

- Management Support

- Focus On The Customer

- Front line Decision Making

- Ongoing Training

- Access To Data

- Managers Trust Employees

- Boundaries Are Clearly Defined

- Employees Have Mentors

- Employees receive positive reinforcement

- Align compensation with customer needs

- Consider social style

- Give employees the tool they need

- Plan for Empowerment 
Modern Empowerment in the Workplace

Kanika Maheshwari

\section{CONCLUSION}

Since the 1980s and the 1990s, Empowerment has been attracting significant interest on the part of both practitioners and theoreticians. Its popularity results from challenges faced by modern organizations. Companies are forced to restrict their control, make their structures more flexible, react swiftly to changes emerging in their surroundings, and utilize the knowledge and skills of their employees.

To include subordinates in decision-making and taking responsibility, it is necessary to view Empowerment from the perspective of an individual - psychological Empowerment, or the standpoint of an organization - organizational Empowerment.

Modern H.R. professionals are leaders in their organizations. The specialists sponsor the organizational mission, vision, values, and goals among staff members, and they monitor and adjust corporate activities to ensure the success of various initiatives. Human resource specialists contribute to enterprises by managing the most crucial asset of any organization, the people who complete the daily tasks that result in productive outcomes - their work aids in the global success of their organizations.

Organizations need to empower their employees or the entire human resources to achieve the actual reality of goals and objectives of 'Make-in-India' vision of the current govt. Of India.

Organizations need to empower their employees or the entire human resources to achieve the actual reality of goals and objectives of 'Make-in-India' vision of the current govt. Of India.

Organizations need to empower their employees or the entire human resources to achieve the actual reality of goals and objectives of 'Make-in-India' vision of the current govt. Of India.

\section{REFERENCES}

[1]. Karim, F., Rehman, O. (2012) Impact of Job Satisfaction, Perceived Organizational Justice and Employee Empowerment on Organizational Commitment in Semi-Government Organizations of Pakistan, "Journal of Business Studies Quarterly," vol. 3, no. 4.

[2]. Leach, D.J., Wall, T.D., (2003), Jackson, P.R., The Effect of Empowerment on Job Knowledge: An Empirical Test Involving Operators of Complex Technology, "Journal of Occupational and Organizational Psychology" March, vol. 76, no. 1.

[3]. Meyerson, G., Dewettinck, B., (2012), Effect of Empowerment on Employees Performance, "Advanced Research in Economic and Management Sciences," 2012, vol. 2.

[4]. Robbins, T.L., Crino, M.D., Fredendall, L.D., (2002), An Integrative Model of the Empowerment Process, "Human Resource Management Review," vol. 12, no. 3, http://doi.org/10.1016/S1053-4822(02)00068-2.

[5]. Sahoo, Ch.K., Das. S., (2011), Employee Empowerment: A Strategy towards Workplace Commitment, "European Journal of Business and Management," 2011, vol. 3, no. 11. 